\title{
The effect of testing conditions on the performance of lost circulation materials: understandable sealing mechanism
}

\author{
Montri Jeennakorn ${ }^{1}$ (I) $\cdot$ Mortadha Alsaba $^{2} \cdot$ Runar Nygaard $^{3} \cdot$ Arild Saasen $^{4} \cdot$ Olav-Magnar Nes $^{5}$
}

Received: 22 May 2017 / Accepted: 10 September 2018 / Published online: 21 September 2018

(c) The Author(s) 2018

\begin{abstract}
Lost circulation materials (LCMs) are added to drilling fluids to mitigate lost circulation (LOC) problems. Designing the fluid requires a good understanding of sealing mechanisms and all the parameters affecting the sealing performance. Laboratory testing apparatus is the key concept for LCM evaluation ensuring successful treatment. The high-pressure test cell containing fracture discs is an effective tool among the broadly designed apparatus. A variety of formulations has been developed from the LCM physical properties. Recently, the testing conditions such as the slot wall angles and the fracture disc thickness were found to have significant effects on the evaluation results. However, the effect of the base fluids, fluid density, types of weighting materials and aging conditions has not been addressed. In this study, two different base fluids, water-based fluids and oil-based fluids, were used to compare the base-fluid effect. Drilling fluid density was raised up using barite and/or hematite to investigate the effect of the weight agents. Barite was sieved to study the effect of fine particles on the sealing. Finally, the dynamic aging tests were conducted in LCM-treated WBF using two temperature levels $\left(200^{\circ} \mathrm{F}\right.$ and $\left.400{ }^{\circ} \mathrm{F}\right)$ and two aging periods ( 24 and $72 \mathrm{~h}$ ). The results showed that the base fluids affected the sealing performance depending on the complex interaction between the solid particles and the fluids. Adding weighting agents tended to improve the seal integrity. Adding proper size of fine particles improved the LCM sealing performance. Aging conditions affected LCM properties depending on the thermal stability of the materials.
\end{abstract}

Keywords Lost circulation $\cdot$ Lost circulation materials $\cdot$ Fractured formation $\cdot$ Fracture sealing $\cdot$ Sealing mechanism

\section{Background}

Lost circulation (LOC) is a challenge for many drilling operators. It significantly increases drilling expenses due to the loss of massive amounts of drilling fluids and potentially loses expensive downhole equipment or even the entire well

Montri Jeennakorn

mj5g4@mst.edu

1 Department of Petroleum Engineering, Missouri University of Science and Technology, 129 McNutt Hall, 1400 N. Bishop, Rolla, MO 65401-0140, USA

2 School of Engineering, Australian College of Kuwait, P.O. Box 1411, 13015 Safat, Kuwait

3 School of Chemical Engineering, Oklahoma State University, 420 Engineering North, Stillwater, OK 74078-7420, USA

4 Department of Petroleum Engineering, University of Stavanger, 4086 Stavanger, Norway

5 Aker BP ASA, PO Box 65, NO-1324, Lysaker Norge, Norway section (Howard and Scott 1951; Clapper et al. 2011; Almagro et al. 2014; Alsaba et al. 2014a; Ghalambor et al. 2014). The problem also consumes some valuable time spent for regaining the circulating system and solving subsequence problems known as the nonproductive time (Salehi and Nygaard 2012; Almagro et al. 2014; Feng et al. 2016). The serious concern is that LOC can lead to a well control issue, which can potentially lead to a life-threatening blowout accident (Horn 1950; Kageson-Loe et al. 2009).

The industry usually performs operations classified as either preventive or corrective approach to eliminate LOC problem (Whitfill and Miller 2008; Kumar and Savari 2011; Ghalambor et al. 2014; Feng et al. 2016). The differences between the approaches are the treatments taken before the main problem occurs as prevention, or after the serious LOC detection as the loss mitigation. Regardless of the method of solving, lost circulation material (LCM) blended with drilling fluids is a common solution for the problems (Robinson 1940; White 1956; Canson 1985; Bourgoyne et al. 1986; Fuh et al. 1992; Alsaba et al. 2014a). The materials might 
be dispersed in the active system or placed as a concentrated mixture against the loss zones (Clapper et al. 2011; Almagro et al. 2014). Proper selection and design process of the LCM treatment is vital to the success of the problem-solving processes.

Laboratory studies were continuously and comprehensively run to understand how LCM works, how to evaluate the performance, and how to improve the sealing ability in the field application (Scott and Lummus 1955; Abrams 1977; Nayberg 1986; Dick et al. 2000; Hettema et al. 2007; Kageson-Loe et al. 2009; Kefi et al. 2010; Clapper et al. 2011; Alsaba et al. 2014b, c, 2016). The knowledge of the sealing behavior, capability and limitation helps in selecting and designing proper LCM raw materials, blending, and treatment processes to be applied in the field operations. The testing results also gain confidence that the sealing would successfully seal at the loss spots as in the test cells. Larger scale field experiments, such as in DEA-13 project (Morita et al. 1990), have been conducted not so often compared to the lower cost laboratory experiments.

As the laboratory studies were conducted to overcome LOC problems, testing apparatus with similar sealing surroundings as in the loss formations was developed to simulate the environment so that the tests represented the actual sealing process as close as possible. To search for the desired materials and formulations, various LCM types with different physical properties and blending were tested in the developed apparatus depending on the objective of the investigations (Alsaba et al. 2014b, c; Hettema et al. 2007; Loeppke et al. 1990; Scott and Lummus 1955).

Focusing on fracture sealing in the impermeable rock matrix, Alsaba et al. (2014c, 2016) presented the effects of LCM type, shape, concentration, particle size distribution (PSD), and temperature on the seal integrity with respect to differential pressure at different fracture widths. It was found that LCM can effectively seal the fractures if the D90 value is equal to or slightly larger than the anticipated fracture width; however, the size of conventional LCM particles is limited by the risk of plugging the downhole tools. The irregular shapes and the ability to deform under pressure of LCM particles promoted the sealing integrity. Increasing the treatment concentration was found to improve the sealing ability within an optimum range, while the broadrange sorting of PSD was needed for a good sealing performance. The effect of fracture width was found to agree with the D90 requirement, and LCM swelling property under higher temperature improved the sealing ability in an LCM formulation.

Jeennakorn et al. (2017) conducted further laboratory investigation of the effect of changing the slot wall angle, the disc thickness, and the instantaneous flow condition on the sealing efficiency. The experiment showed that increasing the slot wall angle tended to decrease the sealing pressure.

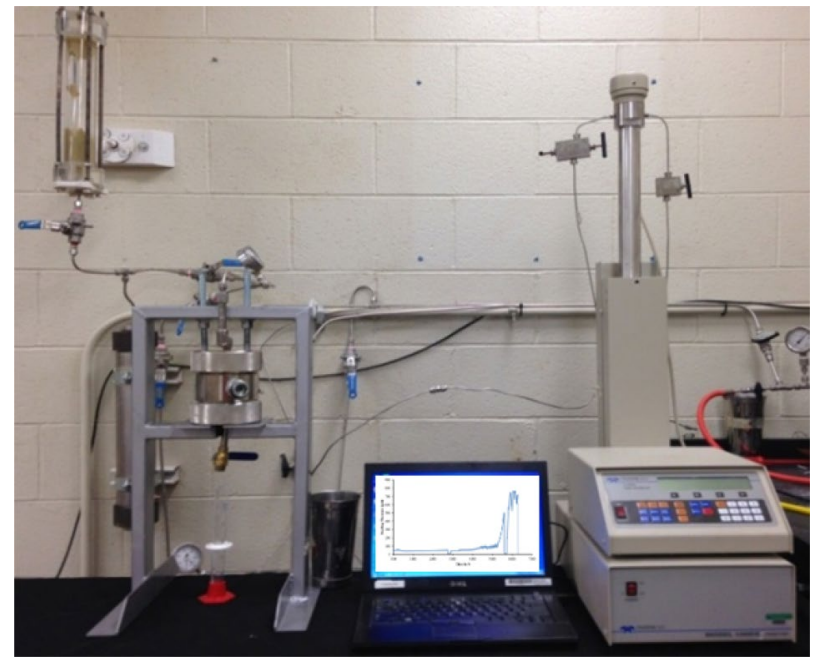

Fig. 1 High-pressure LCM testing apparatus (Alsaba et al. 2014b)

Table 1 Tapered slot specifications

\begin{tabular}{lllll}
\hline Disc code & $\begin{array}{l}\text { Diameter } \\
\text { (inches) }\end{array}$ & $\begin{array}{l}\text { Thickness } \\
\text { (inches) }\end{array}$ & $\begin{array}{l}\text { Slot aperture } \\
\text { (microns) }\end{array}$ & $\begin{array}{l}\text { Slot tip } \\
\text { (microns) }\end{array}$ \\
\hline TS1-R7 & 2.5 & 0.25 & 2500 & 1000 \\
TS15 R-7 & 2.5 & 0.25 & 3000 & 1500 \\
TS2-R7 & 2.5 & 0.25 & 3500 & 2000 \\
\hline
\end{tabular}

Increasing simulated disc thickness in taper slot discs improved the sealing pressure. The study provided some ideas about the effect of testing conditions that change the testing results and should be considered in LCM sealing evaluation. Observation during the experiment provided more understanding about the bridging and sealing mechanism on the simulated fracture discs.

The objective of this study, as a continuous work, is to investigate the effect of the missing testing conditions: the effect of the base fluids, drilling fluid density, weight material types, PSD of weighting materials, and the dynamic aging condition. The experiment was continuously run using the high-pressure LCM tester as an evaluation method (Alsaba et al. 2014b, c, 2016).

\section{Experimental methodology}

\section{The testing apparatus}

The experiment was conducted using the high-pressure LCM tester (Fig. 1) in conjunction with tapered slots that simulate different fracture width ranging from 1000 to 2000 microns (Table 1). The apparatus consisted of four main components: a plastic accumulator used to transfer the drilling fluids to 
the metal accumulator, a metal accumulator used to inject the drilling fluids into the cell, the testing cell that can be pressurized up to $10,000 \mathrm{psi}$, and a high-pressure syringe pump.

Fluids containing LCM treatment are forced to pass through the known fracture width by injecting fluids at a flow rate of $25 \mathrm{ml} / \mathrm{min}$ using the attached Isco ${ }^{\mathrm{TM}}$ pump. Injection continues through the initiation of the seal until a rapid increase in the pressure is observed, which indicates fracture sealing. Once the fracture is sealed, fluids are further pressurized until a significant drop in the pressure is observed due to breaking or leakage of the formed seal. Figure 2 shows an example of the plot of pressure with time; the maximum sealing pressure is the parameter of interest.

\section{Drilling fluid and additives}

Two types of drilling fluids were used in this experiment: water-based fluid (WBF) and oil-based fluid (OBF). The WBF consists of $7 \%$ (by weight) bentonite in $93 \%$ fresh water, $8.6 \mathrm{ppg}$. The WBF might be weighted up with barite or hematite to get a required density of the testing program before mixing with a specific LCM formulation and concentration.

The OBF was a ready-mix environmental-friendly drilling fluid supplied by an oil company with a density of $11 \mathrm{ppg}$. It is known that the original OBF was mixed and contained some amount of barite. To get a lower desired density, the $11 \mathrm{ppg}$ OBF was diluted by adding the base oil ( $6.3 \mathrm{ppg}$ ). To get a higher density, as in the case of WBF, the $11 \mathrm{ppg}$ OBF would also be weighted using barite or hematite.

In this experiment, the effect of base fluid was investigated using two sets of testing where the drilling fluid density for each pair of base fluid was kept constant. The first set of tests using the 7\% bentonite WBF and the diluted $\mathrm{OBF}$ at a density of $8.6 \mathrm{ppg}$ was tested to compare the results. Some of the available testing results from the previous study using WBF (Alsaba et al. 2014a, b) were brought

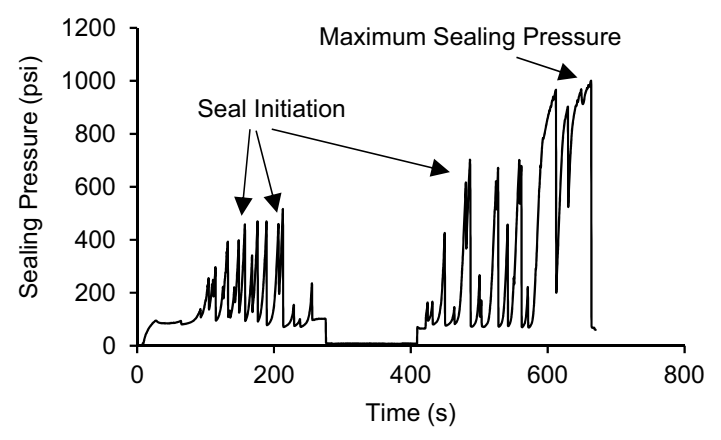

Fig. 2 Pressure vs. time plot obtained from a test using $30 \mathrm{ppb} \mathrm{G}$ and SCC mixed with 14.5 ppg OBF using 1000-micron fracture width. The maximum pressure would be recorded as the sealing pressure in for comparison. In the second set, $\mathrm{OBF}$ at the original density of $11 \mathrm{ppg}$ and the WBF raised up to $11 \mathrm{ppg}$ using barite were used. Both sets of $8.6 \mathrm{ppg}$ and $11 \mathrm{ppg}$ drilling fluids were treated with three different formulations of LCM before being tested in the HPA. The sealing pressures were then used as an indicative variable to study the effect of base fluid on LCM slot sealing performance.

For the effect of drilling fluid density on the sealing pressure, the drilling fluid densities for both WBF and OBF were adjusted to be six different densities varying from 8.6 to $16.5 \mathrm{ppg}$. The WBF was simply weighted up from $8.6 \mathrm{ppg}$ using barite, while the OBF was either diluted with the base oil or barite was added to get the desired densities. The blending of graphite and sized calcium carbonated ( $\mathrm{G}$ and SCC) with a concentration of $30 \mathrm{ppb}$ was used for each sample treatment before being tested in the HPA. The difference in the sealing pressure would indicate the effect of increasing the drilling fluid density on LCM treatment effectiveness.

To study the effect of using different weighting materials, hematite was introduced into the experiment. Along with barite, hematite was added to the OBF (11 ppg) or WBF (8.6 ppg) samples to get a density of $12.5,14.5$, and $16.5 \mathrm{ppg}$. Then, the drilling fluid samples were treated with $30 \mathrm{ppg} \mathrm{G}$ and SCC blend and tested in the HPA. Comparing the same base fluid and density, the effect on the sealing ability of different weighting material can be observed.

When sieving the barite and hematite, the results were slightly different from what was stated in API specification due to the very fine particles that tended to stick to the coarse particles; however, the results presented that hematite contained much finer particles compared to barite. The used weighting materials both came from a reliable manufacturer and met API specification, so it was used for the analysis instead of the sieving results.

By API specification 13A-8.1.2 to 8.1.2, drilling-grade hematite produced from ground hematite ores will have residue particle sizes greater than 45 microns at a maximum mass fraction of $15 \%$ (and greater than 75 microns no more than $1.5 \%$ mass fraction), while the particles smaller than 6 microns will have a maximum mass fraction of $15 \%$. This information implies that at least $70 \%$ mass fraction of the hematite particles is between 6 and 45 microns. One of the previous studies showed that decreasing the particle sizes improves the weighting materials' suspending properties (Xiao et al. 2013). Hematite particles need to be ground finer to get higher surface area per volume (or mass) for easier suspension in the drilling fluids and prevention of sagging problems during circulation.

The effect of fine particles of weighting materials on the sealing ability was validated through an investigation. The $11 \mathrm{ppg}$ OBF using some sieved barite with different ranges of particle size was tested after mixing with LCM. In this paper, both the LCM and the weighting agent underwent a

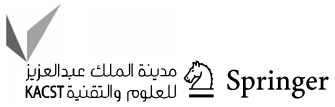


PSD analysis. API specification 13A-7.1.1 states that the standard drilling-grade barite products should have residue particles greater than 75 microns at a maximum mass fraction of 3\% and particle sizes less than 6 microns at a maximum mass fraction of 30\%. Barite particles ranging from 6 to 75 microns can have approximately $67 \%$ mass fraction (or more).

To get the different grade of barite to be mixed with the drilling fluids, the barite was sieved to get three ranges of particle size: course $(\mathrm{C})$, medium $(\mathrm{M})$, and fine $(\mathrm{F})$. The $\mathrm{C}$ particles were larger than 90 microns (remaining on sieve \#170). The M particles were equal to or smaller than 90 microns but larger than 50 microns (passing through sieve \#170 but remaining on sieve \#270). The F particles were 50 microns or finer (passing through sieve \#270). Compared to the specification of hematite above, $\mathrm{F}$ barite particles (50 microns or finer) are very close in size compared to many of the hematite particles (45 microns or finer). Even though using this separating method could not ensure that smaller particles will not remain with the larger one, the fineness grade of the particles in this experiment was efficiently controlled for the smaller sizes, especially in the $\mathrm{F}$ sample.

The result of using the ordinary (no sieve) barite would be available from the effect of density tests; three samples of $12.5 \mathrm{ppg}$ OBF were additionally prepared. They were weighted up to be $12.5 \mathrm{ppg}$ by adding each range of sieved barite, $\mathrm{C}, \mathrm{M}$, or F, respectively. The $12.5 \mathrm{ppg}$ fluid samples were treated with $\mathrm{G}$ and SCC at $30 \mathrm{ppb}$ concentration before being tested in the HPA. The effect of weight agent particle sizes was then achieved by comparing the four sealing pressure results.

Aging tests using aging cells heated in a roller oven were performed to inspect the effect of aging conditions on LCM sealing performance. WBF treated with three different LCM formulations was loaded into the aging cells and placed in the hot rolling oven at a predetermined temperature. After reaching the aging time, the sample was left to cool down to room temperature before testing in the HPA to get the sealing pressure as a performance indicator. The tests were run following the procedure provided in the manufacturer's aging cell instruction manual (OFITE 2013).

\section{LCM formulations}

Table 2 shows seven LCM formulations that were used in this experiment. The blending concentration is shown in pound per barrel (ppb). The specification of each ingredient is indicated by the D50 values as obtained from the material data sheet provided by the manufacturers.

Table 3 presents the PSD regarding D10, D25, D50, D75, and $\mathrm{D} 90$ of the LCM formulation after blending the entire ingredient as indicated in Table 2 and conducting the sieve
PSD analysis. A previous study (Alsaba et al. 2016) proposed that the PSD of the LCM blend affects the formulation sealing ability significantly and is one of the reasons why one LCM formulation gives a different sealing pressure compared to the others. However, the comparison between each formulation is not the objective of this experiment.

\section{Testing results and discussions}

Table 4 shows a summary of the testing results both from the previous studies (Alsaba et al. 2014a, b) and this study. The information will be used to compare between different testing conditions.

Table 5 shows the results from the aging condition tests. Data sets from Tables 4 and 5 will be used for the analysis and discussion.

\section{Effect of base fluids}

Figure 3 shows a comparison between each pair of base fluids with the same density treated with the same LCM formulations. Three pairs of the $8.6 \mathrm{ppg}$ samples are shown on the left-hand side, while three pairs of the $11 \mathrm{ppg}$ samples are shown on the right. All blends were tested using a slot width of 1000 microns (TS1-R7) except the last pairs on the right which were tested with a slot width of 1500 microns (TS15-R7). Results show that different types of base fluids (WBF and OBF) provided different sealing pressures even though they have the same density. Different LCM formulations and concentrations also have different sensitivity to the base fluids.

The first group on the left-hand side shows the results of the three formulations: G and NS; G, SCC and CF; and $\mathrm{G}$ and SCC \#1 with a concentration of 20,55 , and $30 \mathrm{ppb}$, respectively. With the density of $8.6 \mathrm{ppg}$ and considerably lower LCM treatment concentrations, OBF performed better than WBF. The sealing pressure in the G, SCC and CF and (G and SCC \#1) formulations increased by approximately $50 \%$ when used in OBF compared to WBF.

Normally, OBF has a better lubricating property compared to WBF (Bourgoyne et al. 1986). This property can reduce friction between solid contact points and decrease the seal integrity. On the other hand, with the same drilling fluid density, OBF tends to have more solid weight fraction (and volume fraction) than WBF because it contains low-density base fluid. Potentially, the presence of barite particles remaining in the diluted OBF promoted the LCM sealing performance, forming a stronger solid seal and overcoming the lubricating effect. The simple 7\% bentonite WBF containing only bentonite particles and water, with the same LCM treatment with OBF, could not perform as well as the OBF. At this point, the difference in lubricating property and 
Table 2 LCM treatment formulations

\begin{tabular}{|c|c|c|c|c|c|c|c|}
\hline \multirow{2}{*}{$\begin{array}{l}\text { Type and D50 } \\
\text { (microns) }\end{array}$} & \multicolumn{7}{|l|}{ LCM blend } \\
\hline & $\mathrm{G}$ and $\mathrm{SCC} \# 1$ & $\mathrm{G}$ and $\mathrm{SCC} \# 2$ & $\mathrm{G}$ and $\mathrm{SCC} \# 3$ & $\mathrm{G}$ and $\mathrm{SCC} \# 4$ & $\mathrm{G}$ and $\mathrm{NS}$ & $\mathrm{G}, \mathrm{SCC}$ and $\mathrm{CF}$ & NS \\
\hline \multicolumn{8}{|l|}{ Graphite (G) } \\
\hline 50 & 3 & - & - & - & 2 & 2 & - \\
\hline 100 & 3 & - & - & - & 2 & 2 & - \\
\hline 400 & 4.5 & 35 & - & - & 3 & 3 & - \\
\hline 1000 & 4.5 & - & - & - & 3 & 3 & - \\
\hline \multicolumn{8}{|c|}{ Sized calcium carbonate (SCC) } \\
\hline 5 & 1 & - & - & - & - & 2.4 & - \\
\hline 25 & 1 & - & - & - & - & 2.4 & - \\
\hline 40 & - & 35 & - & - & - & - & - \\
\hline 50 & 2 & - & - & - & - & 5.2 & - \\
\hline 400 & 3 & - & - & - & - & 8.4 & - \\
\hline 600 & 4 & - & - & - & - & 10.8 & - \\
\hline 1200 & 4 & - & - & - & - & 10.8 & - \\
\hline 1400 & - & 35 & 70 & 35 & - & - & - \\
\hline 2400 & - & - & - & 35 & - & - & - \\
\hline \multicolumn{8}{|l|}{ Nut shells (NS) } \\
\hline 620 & - & - & - & - & 3.3 & - & 16.6 \\
\hline 1450 & - & - & - & - & 3.3 & - & 16.6 \\
\hline 2300 & - & - & - & - & 3.4 & - & 16.8 \\
\hline \multicolumn{8}{|c|}{ Fine $\mathrm{G}$ and $\mathrm{SCC}$ blend } \\
\hline 500 & - & - & 35 & 35 & - & - & - \\
\hline \multicolumn{8}{|c|}{ Cellulosic fiber (CF) } \\
\hline 312 & - & - & - & - & - & 2.5 & - \\
\hline 1060 & - & - & - & - & - & 2.5 & - \\
\hline
\end{tabular}

Table 3 LCM particle size distribution obtained from blending the formulations in Table 2

\begin{tabular}{lccrrrr}
\hline LCM blend & $\begin{array}{l}\text { Concentration } \\
(\mathrm{ppb})\end{array}$ & \multicolumn{2}{l}{ PSD (microns) } \\
\cline { 3 - 6 } & & $D(10)$ & $D(25)$ & $D(50)$ & $D(75)$ & $D(90)$ \\
\hline G and SCC \# 1 & 30 & 78 & 100 & 460 & 900 & 1300 \\
G and SCC \# 2 & 105 & 65 & 90 & 420 & 1100 & 1400 \\
G and SCC \# 3 & 105 & 90 & 400 & 700 & 1200 & 1400 \\
G and SCC \# 4 & 105 & 170 & 650 & 1300 & 1900 & 2600 \\
G and NS & 20 & 65 & 180 & 500 & 1300 & 1900 \\
G, SCC and CF & 55 & 55 & 100 & 450 & 850 & 1200 \\
NS & 50 & 180 & 400 & 1000 & 1600 & 2400 \\
\hline
\end{tabular}

solid volume fraction between WBF and OBF were believed to be the main factors affecting the sealing efficiency of both the base fluids. The effect of the weighting material particles on the used LCM sealing ability will be evaluated in the following sections when the comparisons were done between the same base fluid.

The $\mathrm{G}$ and NS formulation also sealed better in OBF but had a less increasing sealing pressure between the pair. This formulation was less affected by the base fluids under the testing condition. Considering the PSD of LCM formulations shown in Table 3, the D90 value of the G and NS formulation is 1900 microns, which is much larger than the tested slot width (1000 microns). While the $(\mathrm{G}, \mathrm{SCC}$, and CF) and (G and SCC \#1) formulations have D90 of 1200 and 1300 microns, respectively (Table 3), the D90 sizes are just slightly larger than the tested slot width (1000 microns). The significantly larger size of the bridging particles of NS compared to the slot width might reduce the effect of the base fluids in the G and NS case.

The second group on the right-hand side of Fig. 3 shows the effect of base fluids in a different way (i.e., WBF performed better than OBF). The performance of the other 
Table 4 Summary of the results from previous studies (Alsaba et al. 2014a, b) and this study

\begin{tabular}{|c|c|c|c|c|c|c|}
\hline LCM blend & $\begin{array}{l}\text { Total } \\
\text { LCM } \\
(\mathrm{ppb})\end{array}$ & Base fluid & Disc code & Weighting material & $\begin{array}{l}\text { Base fluid } \\
\text { density (ppg) }\end{array}$ & $\begin{array}{l}\text { Sealing } \\
\text { pressure } \\
\text { (psi) }\end{array}$ \\
\hline$G$ and $N S$ & 20 & $W B M$ & $T S 1-R 7$ & N/A & 8.6 & 2372 \\
\hline$G, S C C$ and $C F$ & 55 & $W B M$ & $T S 1-R 7$ & $N / A$ & 8.6 & 1011 \\
\hline$G$ and $S C C \# 1$ & 30 & $W B M$ & $T S 1-R 7$ & $N / A$ & 8.6 & 487 \\
\hline $\mathrm{G}$ and $\mathrm{SCC} \# 2$ & 105 & WBM & TS1-R7 & Barite & 11 & 2050 \\
\hline $\mathrm{G}$ and $\mathrm{SCC} \# 3$ & 105 & WBM & TS1-R7 & Barite & 11 & 2859 \\
\hline $\mathrm{G}$ and $\mathrm{SCC} \# 4$ & 105 & WBM & TS15-R7 & Barite & 11 & 2571 \\
\hline G and NS & 20 & OBM & TS1-R7 & N/A & 8.6 & 2398 \\
\hline $\mathrm{G}, \mathrm{SCC}$ and $\mathrm{CF}$ & 55 & OBM & TS1-R7 & Barite & 8.6 & 1505 \\
\hline G and SCC \# 1 & 30 & $\mathrm{OBM}$ & TS1-R7 & Barite & 8.6 & 737 \\
\hline $\mathrm{G}$ and $\mathrm{SCC} \# 2$ & 105 & OBM & TS1-R7 & Barite & 11 & 1569 \\
\hline $\mathrm{G}$ and $\mathrm{SCC} \# 3$ & 105 & $\mathrm{OBM}$ & TS1-R7 & Barite & 11 & 1489 \\
\hline G and SCC \# 4 & 105 & OBM & TS15-R7 & Barite & 11 & 1708 \\
\hline \multirow[t]{10}{*}{ G and SCC \# 1} & 30 & WBM & TS1-R7 & Barite & 9.5 & 1205 \\
\hline & & & TS1-R7 & Barite & 11 & 901 \\
\hline & & & TS1-R7 & Barite & 12.5 & 912 \\
\hline & & & TS1-R7 & Barite & 14.5 & 1037 \\
\hline & & & TS1-R7 & Barite & 16.5 & 1344 \\
\hline & & $\mathrm{OBM}$ & TS1-R7 & Barite & 9.5 & 1049 \\
\hline & & & TS1-R7 & Barite & 11 & 1050 \\
\hline & & & TS1-R7 & Barite & 12.5 & 1191 \\
\hline & & & TS1-R7 & Barite & 14.5 & 1214 \\
\hline & & & TS1-R7 & Barite & 16.5 & 1238 \\
\hline \multirow[t]{6}{*}{ G and SCC \# 1} & 30 & WBM & TS1-R7 & Barite + Hematite & 12.5 & 1507 \\
\hline & & & & & 14.5 & 1334 \\
\hline & & & & & 16.5 & 1842 \\
\hline & & $\mathrm{OBM}$ & TS1-R7 & Barite + Hematite & 12.5 & 1269 \\
\hline & & & & & 14.5 & 1305 \\
\hline & & & & & 16.5 & 1283 \\
\hline \multirow[t]{3}{*}{ G and SCC \# 1} & 30 & OBM & TS1-R7 & Barite $(\mathrm{C})$ & 12.5 & 1073 \\
\hline & & OBM & TS1-R7 & Barite (M) & 12.5 & 1134 \\
\hline & & OBM & TS1-R7 & Barite $(F)$ & 12.5 & 1249 \\
\hline
\end{tabular}

The results from the previous study (Alsaba et al. 2014a, b) are italicized three different LCM formulations, G and SCC \#2, G and SCC \#3, and G and SCC \# 4, increased by $30 \%, 92 \%$, and $50 \%$ when they were used in WBF compared to the OBF. One difference between the two groups of results is that in the second group, higher density (11 ppg) drilling fluid samples were treated with a much higher LCM concentration (105 ppb) compared to the first group (8.6 ppg drilling fluid with $20-55 \mathrm{ppb}$ of LCM). It is believed that the higher concentration of the LCM, the higher concentration of barite, and the lubricating property of OBF supported the LCM performance better in WBF environment than in OBF environment. The results presented here provide strong evidence that base fluids do affect the LCM sealing performance. However, its overall effect seems to depend on the type of LCM and should be an area of future investigation.

\section{Effect of density}

Figure 4 shows the sealing pressure from 12 HPA tests over the 1000-micron slot disc after the drilling fluid samples were treated with $\mathrm{G}$ and SCC \#1 at a concentration of $30 \mathrm{ppb}$. The densities of WBF and OBF were adjusted using barite to be six different densities varying from 8.6 to $16.5 \mathrm{ppg}$.

The sealing pressure in OBF was increased by approximately $68 \%$ from 737 to 1238 psi when the fluid density was increased from 8.6 to $16.5 \mathrm{ppg}$. A higher increase of the sealing pressure, $175 \%$ increase from 487 to 1344 psi, was 
Table 5 Aging condition testing results

\begin{tabular}{|c|c|c|c|c|}
\hline Aging condition & $\begin{array}{l}\text { LCM formulation and con- } \\
\text { centration }\end{array}$ & Disc code & Density (ppg) & $\begin{array}{l}\text { Sealing } \\
\text { pressure } \\
\text { (psi) }\end{array}$ \\
\hline \multirow[t]{4}{*}{ No aging } & $\mathrm{NS}, 50 \mathrm{ppb}$ & TS2 R7 & 8.6 & 755 \\
\hline & $\mathrm{G}$ and NS, $40 \mathrm{ppb}$ & TS15 R7 & & 1713 \\
\hline & $\mathrm{G}, \mathrm{SCC}$ and $\mathrm{CF}, 55 \mathrm{ppb}$ & TS1 R7 & & 1011 \\
\hline & $\mathrm{G}$ and $\mathrm{SCC} \# 4,105 \mathrm{ppb}$ & TS2 R7 & 11 & 1606 \\
\hline \multirow[t]{12}{*}{$24 \mathrm{~h} @ 200^{\circ} \mathrm{F}$} & $\mathrm{NS}, 50 \mathrm{ppb}$ & TS2 R7 & 8.6 & 1713 \\
\hline & & & & 750 \\
\hline & & & & 638 \\
\hline & $\mathrm{G}$ and $\mathrm{NS}, 40 \mathrm{ppb}$ & TS15 R7 & 8.6 & 676 \\
\hline & & & & 988 \\
\hline & & & & 1474 \\
\hline & & & & 682 \\
\hline & $\mathrm{G}, \mathrm{SCC}$ and $\mathrm{CF}, 55 \mathrm{ppb}$ & TS1 R7 & 8.6 & 1427 \\
\hline & & & & 1979 \\
\hline & & & & 614 \\
\hline & $\mathrm{G}$ and $\mathrm{SCC} \# 4,105 \mathrm{ppb}$ & TS2 R7 & 11 & 1879 \\
\hline & & & & 1242 \\
\hline \multirow[t]{7}{*}{$72 \mathrm{~h} @ 200^{\circ} \mathrm{F}$} & $\mathrm{NS}, 50 \mathrm{ppb}$ & TS2 R7 & 8.6 & 3021 \\
\hline & & & & 1167 \\
\hline & G and NS, $40 \mathrm{ppb}$ & TS15 R7 & 8.6 & 421 \\
\hline & & & & 1425 \\
\hline & & & & 470 \\
\hline & $\mathrm{G}, \mathrm{SCC}$ and $\mathrm{CF}, 55 \mathrm{ppb}$ & TS1 R7 & 8.6 & 1544 \\
\hline & & & & 1593 \\
\hline \multirow[t]{8}{*}{$24 \mathrm{~h} @ 400^{\circ} \mathrm{F}$} & $\mathrm{NS}, 50 \mathrm{ppb}$ & TS2 R7 & 8.6 & 196 \\
\hline & & & & 136 \\
\hline & $\mathrm{G}$ and $\mathrm{NS}, 40 \mathrm{ppb}$ & TS15 R7 & 8.6 & 99 \\
\hline & & & & 106 \\
\hline & $\mathrm{G}, \mathrm{SCC}$ and $\mathrm{CF}, 55 \mathrm{ppb}$ & TS1 R7 & 8.6 & 1124 \\
\hline & & & & 820 \\
\hline & $\mathrm{G}$ and $\mathrm{SCC} \# 4,105 \mathrm{ppb}$ & TS2 R7 & 11 & 994 \\
\hline & & & & 1105 \\
\hline \multirow[t]{6}{*}{$72 \mathrm{~h} @ 400^{\circ} \mathrm{F}$} & $\mathrm{NS}, 50 \mathrm{ppb}$ & TS2 R7 & 8.6 & 161 \\
\hline & $\mathrm{G}$ and NS, $40 \mathrm{ppb}$ & TS15 R7 & & 104 \\
\hline & $\mathrm{G}, \mathrm{SCC}$ and CF, $55 \mathrm{ppb}$ & TS1 R7 & 8.6 & 111 \\
\hline & & & & 42 \\
\hline & $\mathrm{G}$ and $\mathrm{SCC} \# 4,105 \mathrm{ppb}$ & TS2 R7 & 11 & 3067 \\
\hline & & & & 1790 \\
\hline
\end{tabular}

G and NS $40 \mathrm{ppb}$ is the same formulation and PSD as G and NS 20 ppb formulation but doubled in concentration observed for the same formulation in WBF when the fluid was weighted from 8.6 to $16.5 \mathrm{ppg}$.

Since the only variable that was changed with the fluid density is the increase of the barite particles within the mixture, it is believed that barite particles affect/improve the sealing integrity. From the flattened increase of sealing pressure from 12.5 to $16.5 \mathrm{ppg}$ (Fig. 4) it appears that there might be an optimum point where the proper sizedistributed particles in the system are just right to fill the sealing structure's pore spaces. The LCM performance will not improve beyond that point.

\section{Effect of weighting materials: barite vs. hematite}

From the result of the effect of density tests, some experiments were continued to investigate the effect of changing the weighting material types on the sealing ability. The same G and SCC \#1 blended at 30 ppb was used to treat the 


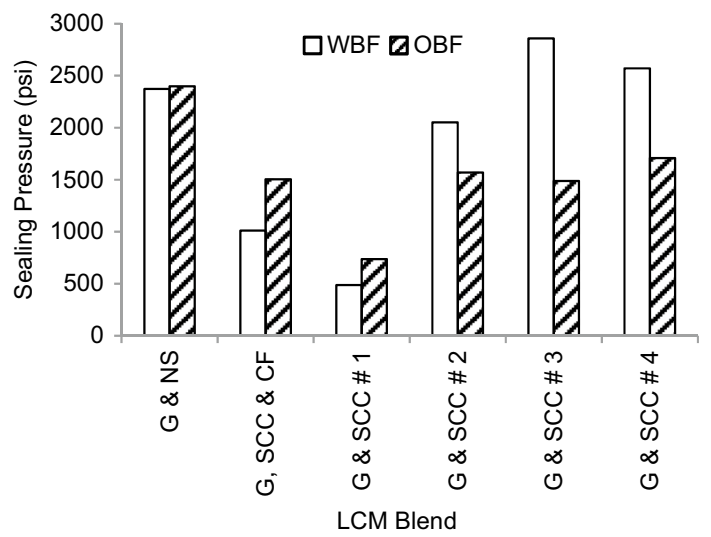

Fig. 3 Base fluid effects on sealing pressure for each LCM formulation. The three pairs of $\mathrm{WBF}$ and $\mathrm{OBF}$ on the left were the results from 20,55 , and $30 \mathrm{ppb}$ varied concentrations, while the three pairs on the right were $105 \mathrm{ppb}$

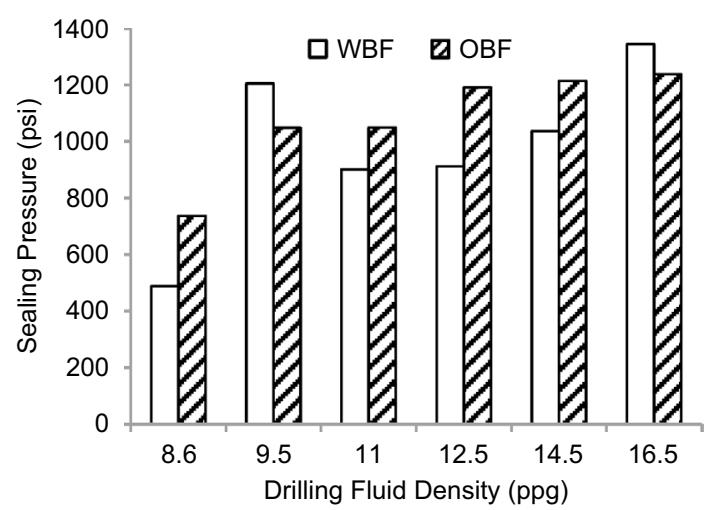

Fig. 4 Effect of increasing the drilling fluid density on the sealing pressure

drilling fluid samples. The $11 \mathrm{ppg}$ OBF (with some amount of barite) and the $8.6 \mathrm{ppg}$ WBF were weighted with hematite to get the desired densities of $12.5,14.5$, and $16.5 \mathrm{ppg}$.

Figure 5 compares the results from using hematite as a weighting agent with the previous results of using barite. The results confirm that in the range of density from 12.5 to $16.5 \mathrm{ppg}$, increasing the density slightly improved the sealing pressure for both WBF and OBF. In OBF, adding hematite into barite-weighted samples resulted in a slight increase of the sealing pressures (broken arrows), but in WBF, using only hematite improved the sealing ability of the LCM treatment significantly (solid arrows).

Figure 6 shows the sealing pressure obtained from the test using different sizes of sieved barite to increase the WBF density from 8.6 to $12.5 \mathrm{ppg}$ before applying G and SCC \#1 treatment at $30 \mathrm{ppb}$. Compared to the regular barite (no sieve), the fluid sample with fine barite (F) gave a better

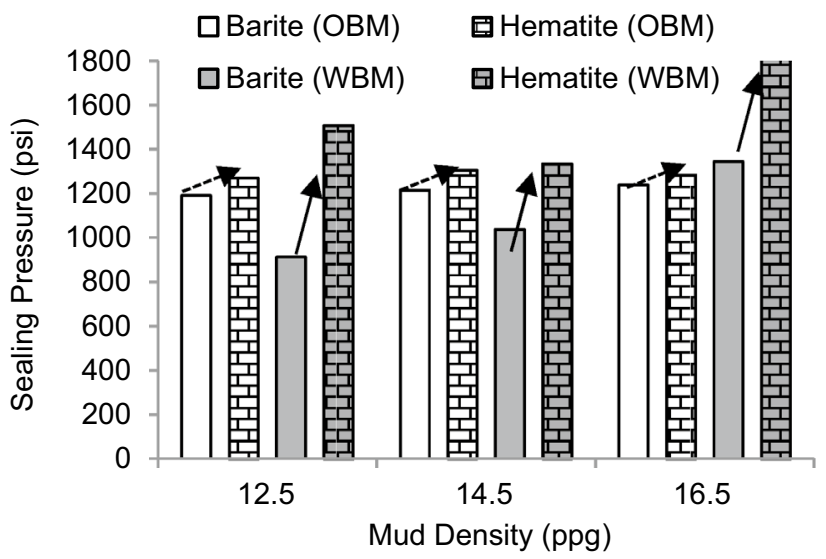

Fig. 5 The effect of weighting materials between barite and hematite. In WBF, the weighting agent used was only barite or hematite, but in $\mathrm{OBF}$, the $11 \mathrm{ppg}$ barite-treated drilling fluid's density was increased to the target density using barite or hematite

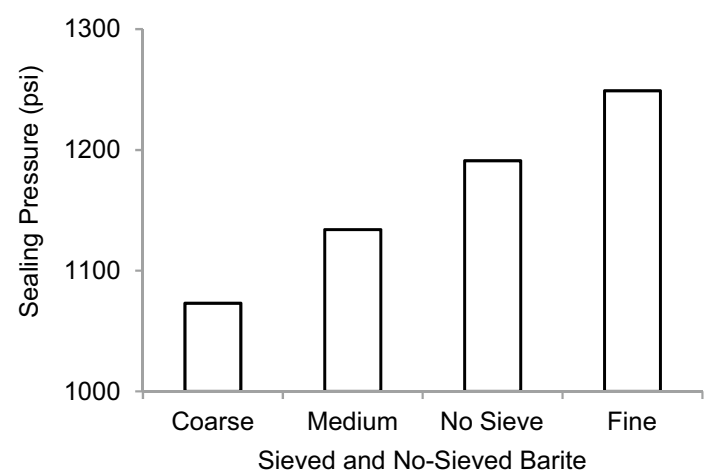

Fig. 6 Effect of adding three ranges of sieved barite particles on the sealing pressures of $12.5 \mathrm{ppg}$ OBF treated with G and SCC \#1 at $30 \mathrm{ppb}$. Variation of barite particle sizes causes the sealing pressures to be varied from 1073 to $1249 \mathrm{psi}$

sealing pressure, while the medium (M) and coarse particles (C) decreased the sealing performance.

Using $\mathrm{F}$ barite brought the sealing pressure up from the case of non-sieve barite (1191 psi) to a higher pressure (1249 psi); it is closer and comparable to the result of the 11-ppg OBM adding hematite (1269 psi) under the same condition. The size of $\mathrm{F}$ barite particles is 50 microns or less, while the size of hematite particles is 45 microns or less for $70 \%$ or more by weight. Considering the PSD of the used LCM formulation ( G and SCC \#1), it is noticeable that this formulation had a D10 value of 78 microns. It was likely that both barite and hematite particles fulfilled the gap-filling requirement of the sealing system, where the improvement was found to be smaller in OBF. However, the results confirmed the idea that weight agent particle size affects the seal integrity. 


\section{Effect of dynamic aging conditions}

This experiment was set up to investigate the effect of aging conditions on LCM performance. Using OFITE aging cells (OFITE 2014) and a rolling oven, two temperature levels were selected to be used. First, a high temperature of $400^{\circ} \mathrm{F}$ was used in the tests to evaluate temperature degradation of LCMs. Second, $200^{\circ} \mathrm{F}$ was used to achieve a normal temperature condition in drilling. Two aging times, 24 and $72 \mathrm{~h}$, were selected to be run as a primary laboratory investigation.

After aging, the drilling fluid samples were moved from the oven and let to cool to room temperature before being tested in HPA. Figure 7 shows the measured sealing pressure of the drilling fluid sample after a specific aging condition compared to non-aged results from previous tests.

At high temperature with aging conditions at $400{ }^{\circ} \mathrm{F}$ (Fig. 7), the NS blend and G and NS blend failed to develop strong seal after applying $400^{\circ} \mathrm{F}$ aging condition for $24 \mathrm{~h}$, but the G, SCC, and CF formulation still had the ability to seal after $24 \mathrm{~h}$, then failed in a $72-\mathrm{h}$ test. The $400{ }^{\circ} \mathrm{F}$ aging condition does not affect the sealing ability of the $\mathrm{G}$ and SCC \#4 formulation for at least $72 \mathrm{~h}$ of the aging test. The thermal stability of the LCM particles controls how LCM performs in the aging tests. Observation provided that the NS particles removed from the disc aperture were so weak that they could be broken easily using fingertips.

Figure 7 also shows the results of the lower temperature aging condition at $200{ }^{\circ} \mathrm{F}$ for $24 \mathrm{~h}$ and $72 \mathrm{~h}$ of aging time.
The NS formulation tends to increase sealing efficiency with aging time. This result confirms the previous study on the effect of temperature on LCM sealing efficiency (Alsaba et al. 2014c).

Inversely, the $\mathrm{G}$ and NS blend (which has $50 \%$ weight of $\mathrm{G}$ ) tends to decrease the sealing ability with the aging time. While the NS improved the sealing pressure, the G strongly decreased the sealing ability of the mixture. The previous study about LCM shear degradation presented the idea about the decrease in size of LCM particles under the dynamic flow of drilling fluids (Valsecchi 2014). The degree of degradation of LCM depends on the density of the particles, the density of drilling fluids, the size of particles, and the fluid viscosity. It was possible that some of the $\mathrm{G}$ particles decreased their sizes under the rolling conditions, resulting in lower sealing efficiency. Further study is needed to understand the behavior of $G$ under these aging conditions.

The G, SCC and CF blend contained only $18 \%$ weight of $\mathrm{G}$, so it was not affected much by the aging conditions, but still gave the same trend as NS, where sealing pressure increased with time of aging. Obviously, CF $(9 \%$ weight) should have the same swelling property as NS that improves sealing pressure under higher temperature. From this experiment, the $\mathrm{G}$ and $\mathrm{SCC} \# 4$ formulation was not affected by the aging condition in terms of sealing efficiency. The formulation contains less than $30 \% \mathrm{G}$, which still showed a good sealing integrity under a 72-h aging time.

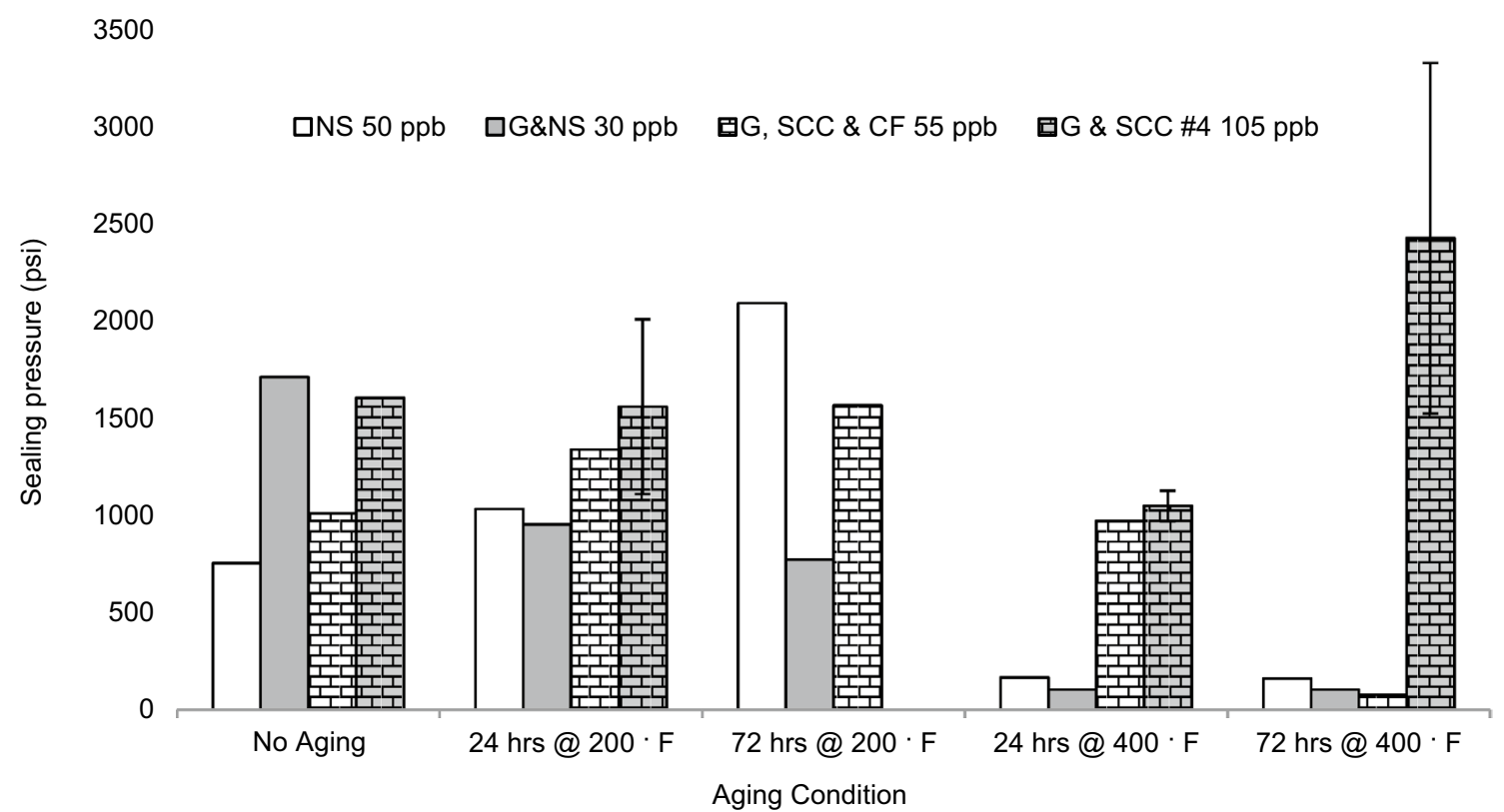

Fig. 7 Sealing pressure of the drilling fluids treated with different LCM after subjected to different aging conditions 


\section{Discussion on sealing mechanism}

This study improves and confirms the authors' understanding of fracture sealing mechanism in impermeable formation. Table 6 summarizes the learning processes and the development of the sealing mechanism idea and shows how the sealing process previously studied by many researchers could be explained using the concept of sealing mechanism. Figure 8 displays how the particles are arranged chronologically in the sealing structure, from coarse particles set downstream on the tip side (as the bridging structure), fine particles (as filling material), and very fine particles (both as filling material and the filtercake-forming material) set upstream on the aperture side.

With previous work of Jeennakorn et al. (2017) and the observation made in this study, the sealing mechanism could be further explained. The sealing structure starts with a bridging formation which creates a permissive environment for the seal body to settle. The stream of drilling fluid flowing through the fracture aperture transport LCM particles into the space between the fracture walls towards the fracture tip. At the starting of the flow, small particles will pass through the flow path between the walls while effectively large particles will set at the point where their sizes match with the space between the fracture walls. The more the bridging particles set in place along the fracture aperture the smaller the flow area of the drilling fluid. The flow is now reduced down to a seepage. The weaker stream will be able to transport some small particles into the available flow paths, forming a porous body. The last step in the sealing process is sealing of the tiny pores on the upstream face. Fine and very fine particles will develop an impermeable membrane as same as the filter cake development on a sandstone wall during a normal over-balanced drilling process, but this time included fine particles of LCM cooperating with fine particles of filtration control agents.

Applying basic engineering mechanics to the seal element, at the instant when the seal was developed and remained in equilibrium, the sum of external forces acting on the seal element in any direction must be zero (Bedford and Fowler 1998). The pressure forces acted within the slot opening area performed by the fluid differential pressure (injecting pressure) was supported back by the slot wall in the form of reaction forces. The load was transferred down the seal from finer grains to the larger particles until it reached the coarsest bridging particles in the slot where no particles set beyond that barrier. When the particles remained in equilibrium, the balance of forces would not allow any particle to move but to stay at rest. Under loading condition, the particles deformed locally at the contact points due to the stress indentation (an elastic, plastic or elastic-plastic type of deformation-depending on the material properties) (Fischer-Cripps 2000). If the load acting on the bridging particles did not exceed the strength of the particles and the sizes of the particles under the local deformation were still greater than the slot space, no part of the seal would fail. On the other hand, if a bridging particle failed or if the local deformation reduced the size of the bridge to be less than the gap between the slot walls, the particle would slip deeper into the slot and finally pushed through the slot. The seal would then suddenly fail because smaller particles behind the bridge can move or flow through the suddenly available flow path (as could be observed on the failed seal removed out of the test cell after the experiments). If the experiment proceeded on, the failure condition would continue on until other coarse particles reformed the bridge and the seal was in equilibrium again. The bridging structure (coarse particles) acted as the foundation or backbone of the seal, playing an important role in the seal development and integrity. From the dynamic aging experiment, the results from many tests showed that the strength degradation of large LCM particles significantly reduced the strength of the bridging particles. The particle sizes was also reduced in the dynamic hot rolling environment.

To understand the seal behavior under the variation of fine grains creating a porous body in the sealing system, one needs reviews in Granular Physics. The forces in the granular system normally are distributed in the form of the "force chains" (Mehta 2007), which is heterogeneous due to different grain sizes, arbitrarily set structure and different spaces. The non-uniform stress distribution tends to weaken the seal structure because it creates a weak point (i.e., the point with a higher local stress that would cause failure while the other points can or try to stay in equilibrium). In this situation, the forces are more difficult to balance. Particles tend to move, and the structure would fail easier if there is no lateral support from the walls.

In this study, the fine barite particles may help occupy the remaining pore space of the seal, either between the solid particles or against the solid particles and the wall. They turn the granule-packed seal into a more homogeneous wedgeshaped object, increase the overall strength of the seal by increasing the contact points within the granular system and improve the force distribution to be more uniform. Increasing the number of contact points and the contact areas also reduces the local stress concentration within the bridging particles, which decreases the magnitude of deformation reducing their grain sizes.

Since forces transmitted at the points of contact are composed of normal forces and frictional (tangential) forces (Johnson 1985), the slot walls support the seal element by both the normal component and the friction component. While the coarse particles set in place as the 


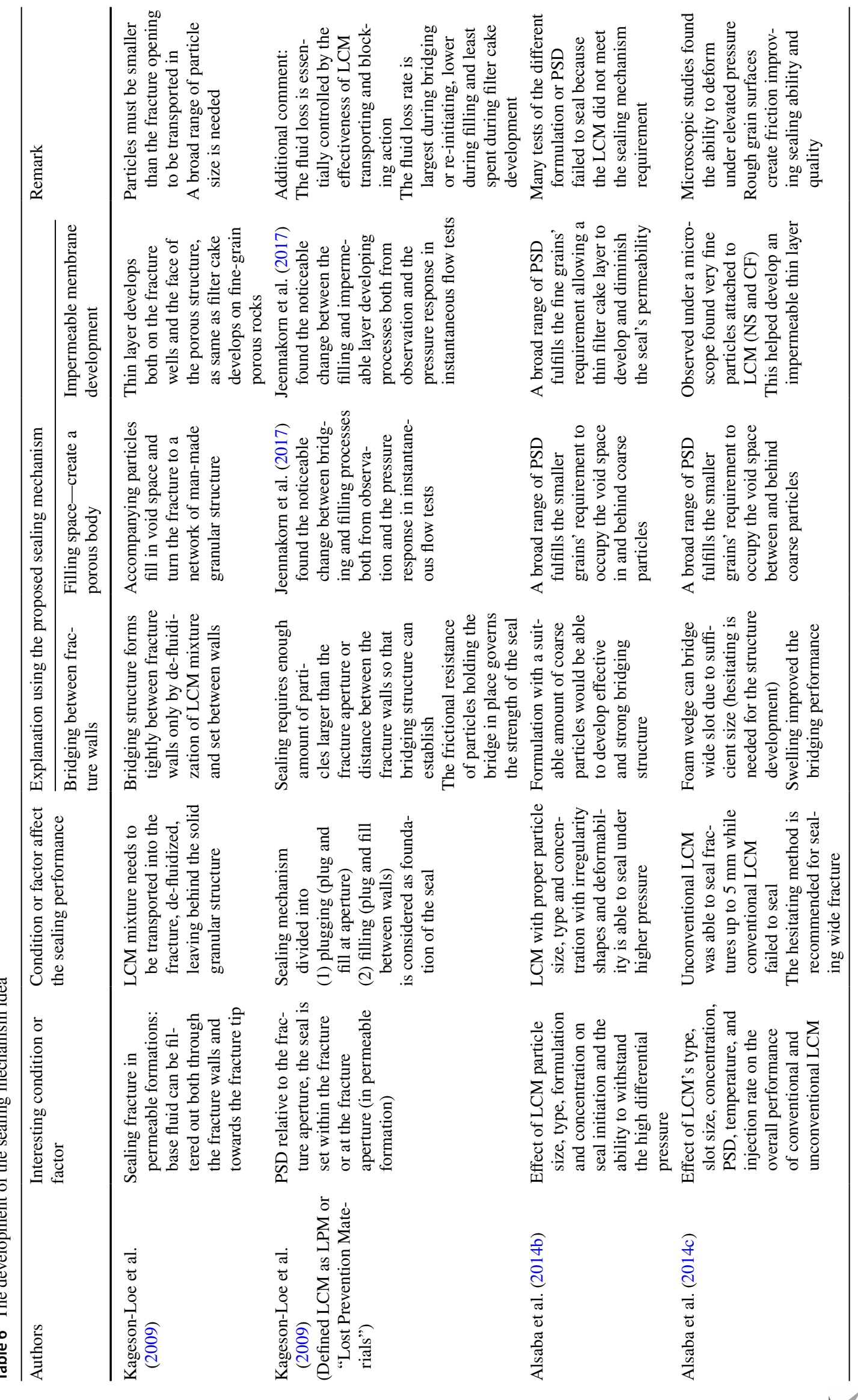




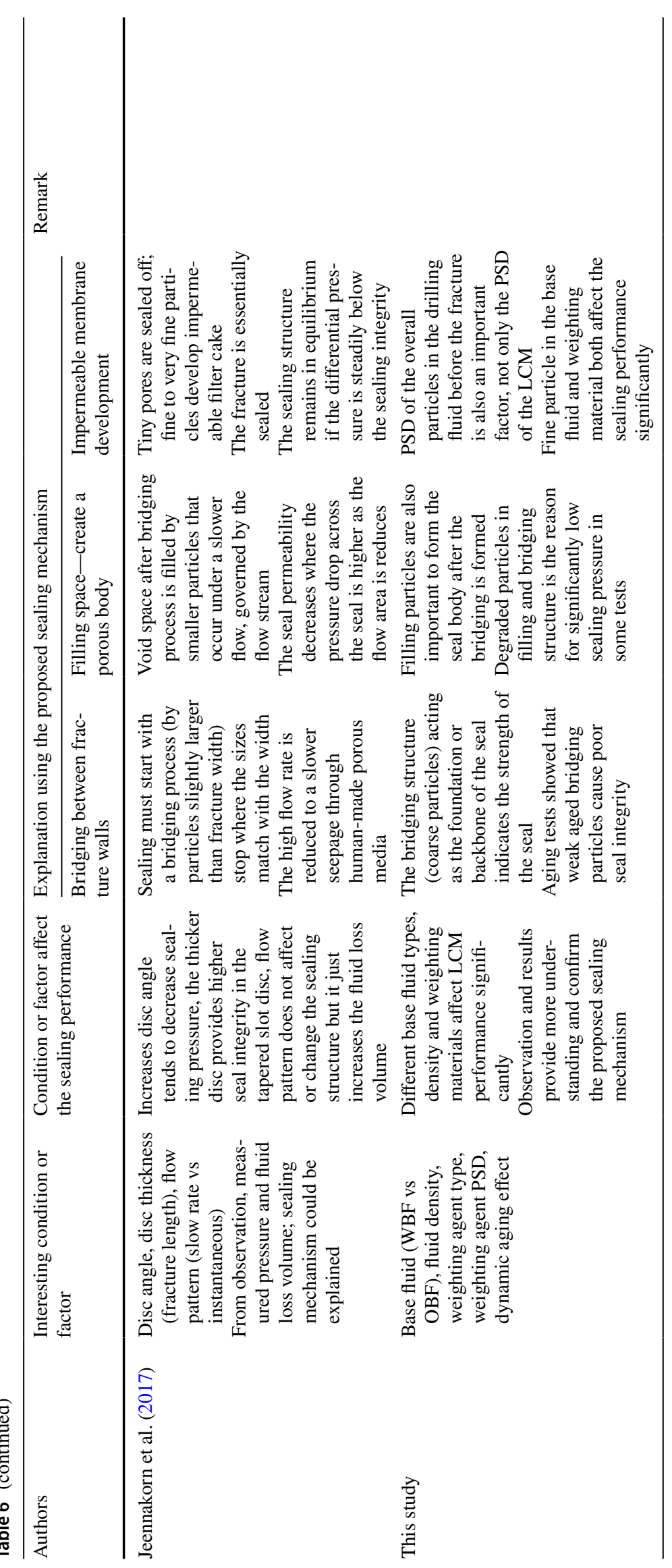



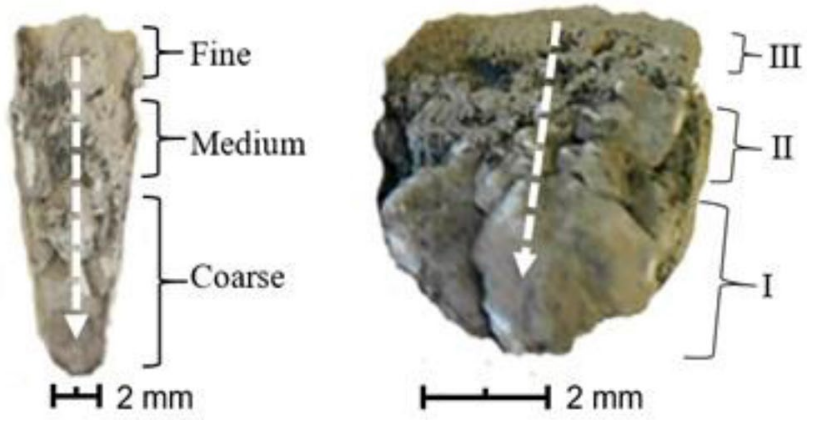

Fig. 8 Close views of the wedge-shaped seal set between the fracture's walls show the grains' sequence set along the flow direction (broken line), looking inline with the fracture plan on the left and from the fracture wall on the right. Three regions of LCM settlement could be observed: I-the bridging structure, II-filling medium particles and III-sealing-off with fine particles and the filter cake. From Jeennakorn et al. (2017)

first barrier, the normal and frictional forces control the equilibrium of the seal. As discussed above, better force distribution improves both the normal and friction force distribution to be more uniform within the seal element. Improving the normal force distribution to the walls also improves the friction, and the better the friction the higher the seal element can withstand the load. Overall, the load can be transferred more uniformly toward the slot walls and better shared among the particles, resulting in higher seal integrity. The results from adding a good portion of fine particles such as adding hematite, barite or fine-sieved barite seem to coherently support this idea. Fine particles appear to stay everywhere they could occupy the void space and essentially contribute in stress distribution of the granular system, but more importantly, they should be the material properties that takes responsibility for the impermeable capability of the seal at the upstream surface.

The finer particles of hematite performed better filling in the pore spaces of the particulate system, providing a stronger seal barrier against the slot walls. Another reason that possibly explains the sealing pressure improvement using hematite comes from the previous study that states the hematite particles are more abrasive than the barite particles (Tehrani et al. 2014). It is believed that the hematite particles not only increase the contact points and contact areas, but also improve the frictional force component (friction coefficient) to be higher than using barite, and help in further increase of the sealing ability of the LCM. Note that OBF contained some amount of barite from the originally supplied drilling fluid. A smaller amount of hematite was added to increase the OBF 11-ppg density to the desired densities compared to WBF, where a larger amount of hematite was added to the 8.6-ppg ( $7 \%$ by weight) bentonite drilling fluid. This might also be one of the reasons why the sealing ability improved less in OBF compared to WBF with the same density.

\section{Conclusion}

- Understandable sealing mechanism obtained from a series of experiments is presented in this article. The knowledge could be applied to LCM treatment selection and design for LOC through the fracture network in the impermeable formation. It should lead to a success both in laboratory and field applications.

- LCM testing using different base fluid types, density and weighting materials affect LCM performance significantly. Caution should be taken when quantitatively comparing LCM tests under such different conditions.

- The properties of the drilling fluid after LCM blending need to be considered instead of the properties of the LCM or the base fluid alone since the base fluids might contain some materials which promote or suppress the sealing capability of the LCM.

- Special blends of weighting material types or properties might be used in a drilling fluid system to enhance fracture sealing capability, especially if LOC is expected during the drilling operation.

- The dynamic aging test provided that time-dependent degradation could occur under severe downhole conditions. LCM selection and the treatment design should take the aging effect into consideration.

Acknowledgements The authors would like to acknowledge Det Norske Oljeselskap ASA (now Aker BP ASA) for the financial support under Research Agreement \# 0037709 to the research group, Dr. Galecki from Missouri University of Science and Technology for his help with the PSD analysis work, and John Tyler and Jeff Heniff from Missouri University of Science and Technology for their assistance in manufacturing the testing apparatus.

Open Access This article is distributed under the terms of the Creative Commons Attribution 4.0 International License (http://creativeco mmons.org/licenses/by/4.0/), which permits unrestricted use, distribution, and reproduction in any medium, provided you give appropriate credit to the original author(s) and the source, provide a link to the Creative Commons license, and indicate if changes were made.

\section{References}

Abrams A (1977) Mud design to minimize rock impairment due to particle invasion. Pet Technol. https://doi.org/10.2118/5713-PA

Almagro BSP, Frates C, Garand J, Meyer A (2014) Sealing fractures: advances in lost circulation control treatments. Oilfield Rev 26(3):4-13. http://www.slb.com/resources/publications/indus try_articles/oilfield_review/2014/or2014aut01_sealing.aspx. Accessed 20 May 2017 
Alsaba M, Nygaard R, Hareland G, Contreras O (2014a) Review of lost circulation materials and treatments with an updated classification. In: AADE fluids technical conference and exhibition, Houston, 15-16 April. AADE-14-FTCE-25

Alsaba M, Nygaard R, Saasen A, Nes O (2014b) Lost circulation materials capability of sealing wide fractures. In: SPE deepwater drilling and completions conference, Galveston, 10-11 Sept. https:// doi.org/10.2118/170285-MS

Alsaba M, Nygaard R, Saasen A, Nes O (2014c) Laboratory evaluation of sealing wide fractures using conventional lost circulation materials. In: SPE annual technical conference and exhibition, Amsterdam, 27-29 Oct. https://doi.org/10.2118/170576-MS

Alsaba M, Nygaard R, Saasen A, Nes O (2016) Experimental investigation of fracture width limitations of granular lost circulation treatments. Pet Explor Prod Technol. https://doi.org/10.1007/s1320 2-015-0225-3 (Accessed 20 May 2017)

Bedford A, Fowler WT (1998) Engineering mechanics: static. AddisonWesley, Boston

Bourgoyne A, Millheim K, Chenevert M, Young FS (1986) Applied drilling engineering. SPE, Richardson, TX

Canson BE (1985) Lost circulation treatments for naturally fractured, vugular, or cavernous formations. In: SPE/IADC drilling conference, 6-8 March, New Orleans. https://doi.org/10.2118/13440-MS

Clapper DK, Szabo JJ, Spence SP, Otto MJ, Creelman B, Lewis TG, McGuffey G (2011) One sack rapid mix and pump solution to severe lost circulation. In: SPE/IADC drilling conference and exhibition, Amsterdam, 1-3 Mar. https://doi.org/10.2118/13981 7-MS

Dick MA, Heinz TJ, Svoboda CF, Aston M (2000) Optimizing the selection of bridging particles for reservoir drilling fluids. In: SPE international symposium on formation damage, Lafayette, 23-24 Feb. https://doi.org/10.2118/58793-MS

Feng Y, Jones JF, Gray KE (2016) A review on fracture-initiation and propagation pressures for lost circulation and wellbore strengthening. SPE Drill Complet. https://doi.org/10.2118/181747-PA

Fischer-Cripps AC (2000) Introduction to contact mechanics. Springer, Berlin

Fuh G-F, Morita N, Boyd PA, McGoffin SJ (1992) A new approach to preventing lost circulation while drilling. In: Annual Technical Conference and Exhibition of the Society of Petroleum Engineers, Washington DC, 4-7 Oct. https://doi.org/10.2118/24599-MS

Ghalambor A, Salehi S, Shahri MP (2014) Integrated workflow for lost circulation prediction. In: SPE international symposium and exhibition on formation damage control, Lafayette, 26-28 Feb. https://doi.org/10.2118/168123-MS

Hettema M, Horsrud P, Taugbol K, Friedheim J, Huynh H, Sanders MW, Young S (2007) Development of an innovative high-pressure testing device for the evaluation of drilling fluid systems and drilling fluid additives within fractured permeable zones. In: Offshore Mediterranean conference and exhibition, Ravenna, 28-30 Mar (OMC-2007-082)

Horn AJ (1950) Well blowouts in California drilling operations causes and suggestions for prevention. API 50:112-128

Howard GC, Scott Jr PP (1951) An analysis and the control of lost circulation. J Pet Technol. https://doi.org/10.2118/951171-G

Jeennakorn M, Nygaard R, Nes O-M, Saasen A (2017) Testing conditions make a difference when testing LCM. J Nat Gas Sci Eng 46:375-386

Johnson KL (1985) Contact mechanics. Cambridge University Press, Cambridge

Kageson-Loe N, Sanders MW, Growcock F, Taugb $\varnothing 1$ K, Horsrud P, Singelstad AV, Omland TH (2009) Particulate-based loss-prevention material-the secrets of fracture sealing revealed! SPE Drill Complet. https://doi.org/10.2118/112595-PA

Kefi S, Lee JC, Shindgikar ND (2010) Optimizing in four steps composite lost-circulation pills without knowing loss zone width. In: Asia Pacific drilling technology conference and exhibition, Ho Chi Minh, 1-3 Nov. https://doi.org/10.2118/133735-MS

Kumar A, Savari S (2011) Lost circulation control and wellbore strengthening: looking beyond particle size distribution. In: AADE national technical conference and exhibition, Houston, 12-14 Apr (AADE-11-NTCE-21)

Loeppke GE, Glowka DA, Wright EK (1990) Design and evaluation of lost-circulation materials for severe environments. SPE Pet Technol. https://doi.org/10.2118/18022-PA

Mehta A (2007) Granular physics. Cambridge University Press, Cambridge

Morita N, Black AD, Fuh G-F (1990) Theory of lost circulation pressure. In: Annual technical conferences and exhibition of the SPE, New Orleans, 23-26 Sept. https://doi.org/10.2118/20409-MS

Nayberg TM (1986) Laboratory study of lost circulation materials for use in both oil-based and water-based drilling muds. SPE Drill Eng. https://doi.org/10.2118/14723-PA

OFI Testing Equipment Inc (2013) High-temperature roller oven with circulating fan instruction manual. Ver. 1.3. http://www.ofite.com/ doc/176-00-C_instructions.pdf. Accessed 20 May 2017

OFI Testing Equipment Inc (2014) Aging cell instruction manual. Ver. 2.13. http://www.ofite.com/doc/175-25_instructions.pdf). Accessed 20 May 2017

Robinson WW (1940) The application of chemicals to drilling and producing operations. API 40:236-245

Salehi S, Nygaard R (2012) Numerical modeling of induced fracture propagation: a novel approach for lost circulation materials (LCM) design in borehole strengthening applications of deep offshore drilling. In: SPE annual technical conference and exhibition, San Antonio, 8-10 Oct. https://doi.org/10.2118/135155-MS

Scott PP Jr, Lummus JL (1955) New developments in the control of lost circulation. In: Annual Fall meeting of the Petroleum Branch of the American Institute of Mining and Metallurgical Engineers, New Orleans, 2-5 Oct. https://doi.org/10.2118/516-G

Tehrani A, Cliffe A, Hodder MH, Young S, Lee J, Stark J, Seale S (2014) Alternative drilling fluid weighting agents: a comprehensive study on ilmenite and hematite. In: IADC/SPE drilling conference and exhibition, Fort Worth, 4-6 Mar. https://doi. org/10.2118/167937-MS

Valsecchi P (2014) On the shear degradation of lost-circulation materials. SPE Drill Complet. https://doi.org/10.2118/163512-PA

White RJ (1956) Lost-circulation materials and their evaluation. In: Drilling production practice, pp 352-359, API 56-352

Whitfill DL, Miller M (2008) Developing and testing lost circulation materials. In: AADE fluids conference and exhibition, Houston, 8-9 Apr (AADE-08-DF-HO-24)

Xiao J, Nasr-El-Din HA, Al-Bagoury M (2013) Evaluation of ilmenite as a weighting material in oil-based drilling fluids for HPHT applications. In: SPE European formation damage conference and exhibition, Noordwijk, 5-7 June. https://doi.org/10.2118/16518 4-MS

Publisher's Note Springer Nature remains neutral with regard to jurisdictional claims in published maps and institutional affiliations. 